\title{
O Ensino de Língua Inglesa, a política e os cursos técnicos ${ }^{1}$
}

\section{English Language Teaching, policies and technical courses}

\author{
Francieli de Oliveira ${ }^{2}$
}

\section{Resumo}

O trabalho tem por objetivo realizar uma discussão teórica sobre o regimento político atual, o desenvolvimento do ensino de línguas e sua importância no contexto social de cursos técnicos. Apresentamos algumas razões para implementação dos cursos técnicos, de que forma se dá o ensino de línguas nesse contexto, mais especificamente Língua Inglesa, e qual a qualidade desse ensino nestes. Num primeiro momento, apresentamos um pequeno levantamento de qual é a política atual do país e em seguida quais as consequências que esse regimento traz ao ensino de Língua Inglesa nos cursos citados anteriormente. Posteriormente apresentamos o ensino da língua nos cursos técnicos e a melhor abordagem para seu ensino e por fim, fazemos uma análise da sequência didática elaborada no ano de 2008 para a disciplina de estágio em um curso técnico de um colégio localizado em Guarapuava - Pr.

Palavras chaves: políticas, cursos técnicos, técnicas de leitura

\begin{abstract}
This project aims to carry out a theoretical discussion about the current political regime, the development of language teaching and its importance in the social context of technical courses. We present some reasons for implementing technical courses, how language teaching takes place in this context, especially the English language, and the quality of education in these courses. At first, we present a short survey of what the current policy of the country is, followed by the consequences this regime brings to English Language teaching in the previously mentioned courses. Subsequently, we present the English teaching in technical courses and the best teaching approach, and finally, we analyze a didactic sequence elaborated in 2008 for the practicum discipline in a technical course of a school located in Guarapuava - PR.
\end{abstract}

Keywords: policies, technical courses, reading techniques

\section{Introdução}

Com a globalização e o advento da internet as notícias atualmente são rapidamente divulgadas, os cidadãos têm contato com todo o mundo e, dessa forma, o ensino de Língua Inglesa (LI) tem sido mais propagado e essencial para que seja possível a comunicação, negociações e a leitura de notícias.
Também o processo de desenvolvimento do mercado de trabalho tem exigido muito mais especialistas em cada área de atuação, com qualificação, do que pessoas que fazem ou sabem tudo (TOZONI-REIS, 2008). Brydon (2011) expõe que o "processo de globalização tem mudado formas de entender o conhecimento, aprendizado, letramento, e ensino

\footnotetext{
${ }^{1}$ Este artigo é parte da dissertação desenvolvida no curso de pós-graduação mestrado em Estudos da Linguagem - UEL.

${ }^{2}$ Mestranda em Estudos da Linguagem na área de Ensino/Aprendizagem e Formação de Professores de Língua Estrangeira pela Universidade Estadual de Londrina. Email: fran_oliveira_23@hotmail.com.
} 
de inglês ${ }^{3} . "(B R Y D O N, 2011$, p. 96). O contato tanto pessoal quanto a negócios se tornou rápido e eficaz com a aquisição e o rápido desenvolvimento da tecnologia. Com isso, falar várias línguas se tornou fator essencial e de destaque na sociedade atual. Brydon ainda cita que conhecer mais de uma língua é incrivelmente reconhecido sendo vantajoso no conhecimento social (BRYDON, 2011, p. 96). Ter uma boa carreira e posição social exige grandes responsabilidades e comprometimento com o conhecimento adquirido e quanto mais conhecimento maior a sua classificação e destaque profissional. Por isso, neste trabalho, discutimos o desenvolvimento da política atual, o neoliberalismo no mercado de trabalho e a sua influência no ensino de língua inglesa em cursos de ensino técnico.

Os referidos cursos tiveram crescimento após o decreto da LDB (Lei de Diretrizes e Bases) de 1996 (BRASIL, 1996), que tem como pressuposto que as escolas deem aos alunos o direito de receber a educação apropriada ao mercado de trabalho permitindo que eles efetuem essa "transição entre escola e mundo de trabalho". O governo visa à habilitação dos aprendizes de cursos técnicos como profissionais de áreas específicas qualificandoos para o mercado. Dessa forma, surgem então os cursos técnicos, que propõem o desenvolvimento das capacidades dos alunos já os certificando para áreas específicas e para essas necessidades econômicas. Nesse artigo, iremos apresentar os conceitos de cursos técnicos segundo alguns teóricos, qual a corrente política que o influencia e qual a sua abordagem no ensino dessa língua.

\section{Os cursos técnicos}

Sabbi (2005) afima que os cursos técnicos têm como proposta "competitividade, individualidade, meritocracia, redução de custos de formação humana e formação orientada apenas pelas necessidades do mercado" (SABBI, 2005, p. 37). $\mathrm{Na}$ visão do autor então, a capacitação dos alunos se dá pelas necessidades do mercado de trabalho pela qual o governo observa quais são as falhas sociais em determinadas áreas e por meio dessas áreas decidirá o curso técnico que será ofertado para suprir a carência social. $\mathrm{O}$ autor ainda explica que esta necessidade se dá pelo aumento da agilidade no desenvolvimento de atividades particulares, as tarefas devem ser práticas e assim cada qual exercerá uma função específica em seu local de trabalho. Essas escolas técnicas foram então implementadas para o setor produtivo (SABBI, 2005, p. 37).

Podemos observar que os cursos se destinam à população de classe média baixa, pois a demanda desses cursos são de urgência e o público que tem a urgência em adquirir uma profissão pertence a essa classe, pela falta de condições de continuar os estudos, pois muitos necessitam auxiliar as despesas da casa. Alunos de classe alta se capacitam em cursinhos pré-vestibular e, consequentemente, tem o privilégio de escolher a profissão que desejam já se preparando para ela. Saviani (2008) denomina a primeira situação como o "aligeiramento do ensino", que se direciona às camadas populares nos casos em que, ao invés de passar três anos no Ensino médio com um Ensino geral e outros quatro anos ou cinco anos na universidade, a população de classe média opta por diminuir essa carga cursando o técnico e sair diplomado para o desempenho da profissão em menos tempo. O autor então levanta duas teorias acerca da educação, sendo a primeira a que equaliza, e a segunda a que exclui a camada social (SAVIANI, 2008). Concluímos que a disposição de cursos técnicos, os quais são aproveitados apenas por alunos de classe média com urgência em se engajar no mercado de trabalho seria uma forma de discriminação. Mascarada a necessidade social, a justificativa dada à implementação de cursos técnicos é que por meio deles as taxas de

3“Globalizing processes are changing understandings of knowledge, learning, literacy, and English teaching” 
desemprego serão diminuídas, contribuindo com a atual estrutura da sociedade (SABBI, 2005), então "a escola surge como um antídoto à ignorância" (SAVIANI, 2008). Shiroma, Moraes e Evangelista (2002) chamam essa criação do Ensino Técnico como uma separação entre o técnico e o médio, tornando-o profissionalizante e nas palavras das autoras encaminhando "jovens de classes sociais" diferentes para outras trajetórias educacionais e sócio-econômicas (SHIROMA; MORAES; EVANGELISTA, 2002, p. 92). A classe social da camada popular já é escolhida e determinada na disposição de cursos, os quais mantém os jovens na mesma posição em que se encontram, pois são poucos os que têm a "sorte" de ir além do curso profissionalizante ou técnico.

Essa visão surge da corrente política que tem sido implementada no Brasil, o neoliberalismo. De acordo com Bianchetti (2001), o neoliberalismo é a atenção ao estado e às suas necessidades. Os cidadãos são livres para decidir o que desejam, porém são induzidos a agir de acordo com os interesses do estado sem que percebam que essa ação está acontecendo. A responsabilidade pelo fracasso ou pelo sucesso é individual de cada ser sendo ele o próprio responsável por ambos. Smith (1996) expõe que cada indivíduo na vida adulta é "totalmente independente" e não precisa da ajuda de nenhum outro ser. $\mathrm{O}$ autor afirma que o indivíduo social age de acordo com seus interesses pessoais e seus benefícios, mas quando em coletividade, deve agir para o bem do grupo no sentido econômico, podendo ser estendida aos outros setores sociais. $\mathrm{O}$ sujeito é forçado, ainda que discretamente, a pensar no coletivo. O setor superior e dominante utiliza-se de políticas sociais para obter um interesse "social", porém visa a um bem específico, e faz uso assim de políticas influenciadoras (BIANCHETTI, 2001, p. 89). Como exemplo desse interesse os cursos técnicos.

Se observarmos a demanda social e a disponibilização desses cursos, temos um exemplo claro dessa influência. É normal que tenham falhas no mercado de trabalho com a falta de profissionais em determinadas áreas e o governo disponibiliza cursos técnicos para que essa lacuna seja preenchida. Cada sujeito social procura a oportunidade que lhe é dada e é responsável individualmente por aquilo que alcança sendo esse resultado fracasso ou sucesso. Bianchetti defende que "O volume dos resultados individuais e coletivos está determinado pela sorte e pela decisão individual", portanto "a noção de justiça social é considerada como uma forma de intervenção externa na busca de igualdade de resultados" (BIANCHETTI, 2001, p. 91). Shiroma, Moraes e Evangelista questionam essa situação, os jovens não vão além do ensino médio, e ao mesmo tempo o estado "imputa-lhe caráter terminal e adequados às demandas do mercado de trabalho" (SHIROMA; MORAES; EVANGELISTA, 2002, p. 115). Observamos que as ofertas são disponibilizadas de acordo com a necessidade social e os jovens são induzidos a tomar as decisões de acordo com elas, e, dessa forma, direcionam seu futuro ao que lhes é imposto. Tozoni-Reis (2008) apresenta o ensino universitário como uma contradição, "de um lado" o ensino é colocado "a serviço da formação das elites dirigentes e de outro, produz conhecimentos críticos, na interpretação das relações sociais contraditórias, para seu enfrentamento e transformação." (TOZONI-REIS, 2008, p. 84) Frigotto, no prefácio do livro Modelo neoliberal e Politica educacional de Bianchetti (2001) faz uma crítica ao estado com o seguinte argumento, "o receituário neoliberal é eficiente para uma sociedade de poucos incluídos e a maioria excluídos. Eficiência esta cujo escopo é o aumento de toda a espécie de violência e barbárie." (BIANCHETTI, 2001, p. 15), a limitação de crescimentos social acarreta a estagnação e esta a inconformação, a revolta, portanto cidadãos que não conseguem destaque social optam por alternativas erradas de crescimento financeiro.

Juntamente com a limitação social, que torna a população de classe média dependente de classes superiores limitados com a separação entre o que podem e o que devem fazer, contamos com o 
ensino de Línguas Estrangeiras (LE) nos cursos técnicos, uma exigência social que, na maioria das vezes, acaba sendo ineficaz pela falta de condições apropriadas de ensino. Em geral, quando falamos em Ensino de Línguas, nesse estudo (LI), a primeira ação de linguagem ${ }^{4}$ que nos remete é a fala. Muitos que iniciam um curso de inglês, em escolas de idiomas ou na escola regular, visam a falar outra língua, o problema é que em cada contexto social, a língua é abordada de uma forma. Kalva e Penteado (2011) questionam em seu estudo qual ação de linguagem seria a mais importante para os alunos. As autoras concluem, de acordo com o contexto encontrado por elas, que a ação que condiz com a real necessidade dos alunos é a leitura, sendo que o professor irá ensinar técnicas aos alunos para que eles possam reconhecer conceitos e o sentido geral do texto.

Visando a proporcionar ao aluno a capacidade de entender os textos, Cristovão (2009) propõe o uso de ações de linguagem para a leitura de um texto, sendo que o envolvimento de um aluno com um texto "envolve uma determinada ação de linguagem” (CRISTÓVÃO, 2009, p. 318). Em primeiro lugar, para que haja o ensino de leitura, segundo a autora, o professor deverá fazer uso de um gênero que atenda as necessidades do aluno.

Para a compreensão desse texto, o professor e o aluno fará uso das capacidades de linguagem que são: capacidade de ação, capacidade discursiva e linguístico discursiva. Incluímos neste trabalho a capacidade de significação (CRISTOVÃO; STUTZ, 2011).

De acordo com Cristovão (2009), a capacidade de ação está relacionada ao conhecimento do aluno com relação à produção do texto, à quem o produziu, à quem esse texto se dirige, o porque e qual o contexto social no qual ele se situa. A capacidade discursiva diz respeito à "infraestrutura geral de um texto" (CRISTOVÃO, 2009, p. 321), as formas de organização desse texto e "Reconhecer a organização do texto como layout" (CRISTOVÃO et. al., 2010, p. 194). A capacidade linguístico discursiva são as “operações implicadas na produção textual” (CRISTOVÃO, 2009, p. 321), ou seja, as estruturas lexicais e gramaticais movidas para a construção textual. A capacidade de significação é o desenvolvimento de sentido para as funções do texto na sociedade e qual é o impacto que ele terá nas formas de ação do indivíduo (CRISTOVÃO; STUTZ, 2011).

Cristovão (2009), citando Vygotsky (1934/1993), defende que por meio das capacidades da linguagem uma pessoa, nesse caso o aluno, pode desenvolver uma ação de linguagem, e "essa mesma abordagem pode ser estendida à questão da leitura" (CRISTOVÃO, 2009, p. 322). Dessa forma, o aluno, fazendo uso das capacidades de linguagem, seria capaz de compreender o texto por meio do contexto de uso, da significação do texto no mundo, da estrutura textual e dos conteúdos linguísticos que o compõem. Por isso, adotamos essa forma de ensino da compreensão leitora.

A autora também cita a possibilidade do uso de textos em língua materna para tornar a compreensão do aprendiz mais eficaz, pois, os tendo como exemplo, poderá fazer relações com o texto de língua estrangeira.

Juntamente com as capacidades de linguagem, Cristovão et. al. (2011) propõe o uso das técnicas de leitura. Segue abaixo um quadro com a explicação das possíveis técnicas de leitura a serem utilizadas em acordo com as capacidades apresentadas pelos autores:

\footnotetext{
${ }^{4}$ Ação de linguagem termo sugerido por Cristovão (2009) para substituir habilidade.
} 
Quadro 1 - Técnicas de leitura

\begin{tabular}{|c|c|}
\hline Skimming & $\begin{array}{l}\text { Ler para a compreensão geral do texto, iniciando por título, } \\
\text { subtítulos, informações não-verbal (como gráficos, figuras, } \\
\text { etc.) e, por último, o texto propriamente dito. }\end{array}$ \\
\hline Scanning & $\begin{array}{l}\text { Ler para a busca de informações específicas, partindo das } \\
\text { palavras-chave ou outros recursos que ajudem o leitor } \\
\text { nessa identificação. Por exemplo, se ele precisa encontrar } \\
\text { um dado referente a um telefone, saberá que deve procurar } \\
\text { por números de telefone (que são, no Brasil, normalmente } \\
\text { formados por } 8 \text { dígitos divididos em } 2 \text { grupos de } 4 \text { ). }\end{array}$ \\
\hline Reconhecimento de cognatos & $\begin{array}{l}\text { Prestar atenção nas palavras da língua estrangeira (inglês, } \\
\text { neste caso) que se assemelham a língua materna (língua } \\
\text { portuguesa, neste caso), seja no aspecto gráfico ou fonético, } \\
\text { como, por exemplo, penalty, taxi, etc. }\end{array}$ \\
\hline Antecipação & $\begin{array}{l}\text { Prever o que está por vir, com base em informações } \\
\text { explícitas e em suposições, como: o título e a imagem; } \\
\text { palavras mais frenquentes, etc. }\end{array}$ \\
\hline Inferência & $\begin{array}{l}\text { Compreender, interpretar o que não está no texto de forma } \\
\text { explícita, com base em indicações do texto, no contexto, } \\
\text { bem como em seu conhecimento. Essas inferências } \\
\text { contribuem para o processo de construção de significados, } \\
\text { podendo ser confirmadas ou não. }\end{array}$ \\
\hline Leitura extensiva & $\begin{array}{l}\text { Ler em quantidade com o intuito de obter compreensão } \\
\text { geral do que se lê. Contribui para o desenvolvimento dos } \\
\text { bons hábitos de leitura, a ampliação do desenvolvimento } \\
\text { de vocabulário e de estrutura da língua. }\end{array}$ \\
\hline $\begin{array}{l}\text { Reconhecimento de } \\
\text { grupos nominais }\end{array}$ & $\begin{array}{l}\text { Identificar grupos nominais relevantes ao texto contribui } \\
\text { para a percepção de palavras essenciais à compreensão } \\
\text { do texto e ao reconhecimento de ideias centrais. Saber a } \\
\text { organização das palavras nos grupos nominais facilita sua } \\
\text { identificação. }\end{array}$ \\
\hline Uso de dicionários & $\begin{array}{l}\text { Procurar palavras desconhecidas essenciais à compreensão } \\
\text { de um texto (escrito ou oral) contribui para sua melhor } \\
\text { compreensão e para a ampliação de vocabulário. Deve } \\
\text { ser realizada quando não for possível reconhecer seu } \\
\text { significado apenas pelo contexto. }\end{array}$ \\
\hline
\end{tabular}

Fonte: Cristovão, et. al. (2011, p. 204) 
Abordando mais especificamente a situação apresentada, nesse caso os cursos técnicos, a expectativa do aluno de LI não deve ser falar a língua e sim ler os textos técnicos que irá encontrar no decorrer de sua carreira como tecnólogo. Pensando nisso, os futuros licenciados ou já profissionais da língua devem trazer aos alunos gêneros de textos, sejam eles escritos ou orais, condizentes com a temática do curso em que eles estão lecionando, e ainda, ter o conhecimento suficiente para trabalhar com estes em sala.

Fato é que os cursos de licenciatura em Letras não têm prazo suficiente para capacitar os professores de LI para as diferentes abordagens exigidas socialmente. A maioria dos alunos que entram no curso acredita que com a formação eles sairão da graduação fluentes em LI. Fernandéz (2008) diz que a duração dos cursos torna o fator qualidade inexequível. O tempo é limitado para que se alcance a fluência desejada na língua, a formação teórica e a experiência necessária. A autora (FERNANDÉZ, 2008) cita que os estudantes possuem pouco tempo de estágio para atingir a experiência necessária e esse fato associa-se a alguns fatores: a língua não é a desejada, LE com carga reduzida, turmas numerosas, falta de articulação entre conteúdo específico e pedagógico, somente o estágio sem nenhuma disciplina que aborde metodologia ou prática de ensino, a dificuldade da observação e por fim, em muitos cursos, não é necessário que haja a prática para que o aluno adquira a certificação de licenciado e possa exercer a profissão sem a preparação necessária. Com esses fatores negativos, a grande maioria dos professores de LI em cursos técnico trabalham em sala com textos de tema geral e diferentes daqueles que os alunos necessitam ler.

Shiroma, Moraes e Evangelista levantam então uma questão: "Como se pode ter expectativa de melhorar a aprendizagem atribuindo mais alunos aos professores que, por vezes, possuem o mesmo nível de formação no qual lecionam?" (SHIROMA; MORAES; EVANGELISTA, 2002, p. 107). Por vezes encaramos professores que possuem o mesmo nível de inglês dos alunos do curso, ou ainda abaixo, e que devem compartilhar o conhecimento aos alunos. Celani (2010) diz que "a formação pré-serviço é inadequada e insuficiente." e ainda que "De fato, não se aprende com professores despreparados.”(CELANI, 2010, p. 61). Isso, na maioria das vezes, acaba causando constrangimento ao professor, que não tem noção e nem a preparação necessária para auxiliar o aluno na aprendizagem da língua. Para ensinar termos técnicos, o professor de LI em primeiro lugar tem de procurar por conhecimento, e. na grande maioria, eles não são formados na área do curso no qual lecionam e por isso ignoram o conteúdo ali disposto. Esse problema surge por causa da falta de tempo de preparação, pois se sobrecarregam com várias cargas horárias de trabalho, muitas vezes em escolas diferentes e têm de preparar todas essas aulas para poder atender a demanda. Isto ocasiona uma preparação geral, com temas que não tem relação alguma com o conteúdo técnico que deveria ser trabalhado. Ao contrário, ele busca por temas fáceis para que possa dar conta de todas as aulas que deve produzir. Isso então acaba resultando na deficiência do ensino de línguas nos cursos técnicos.

\section{A Experiência}

Como aluna do curso de Letras da UNICENTRO - Universidade Estadual do Centro-Oeste - no quarto ano do curso de Letras Inglês e suas literatures - tive decumprir a carga de estágio obrigatório. Foi decidido então que faria isso numa escola do centro da cidade que possui Ensino Médio regular e também cursos técnicos. Eu e meu colega de estágio acabamos escolhendo o curso técnico em meio-ambiente, pelo desafio de ensinar nesse curso e também pelo horário das aulas.

Se analisarmos as necessidades da sociedade atual, é viável a oferta de cursos técnicos em meio ambiente, pois há a disponibilização de uma nova 
área de trabalho, a qual é responsável pelo equilíbrio ecológico e que terá a ajuda dos técnicos com as seguintes tarefas:

1. Supervisionar a execução de atividades florestais, desde a construção de viveiros florestais e infra-estrutura, produção de mudas e colheita florestal até o manejo de florestas nativas.

2. Inventariar florestas e planejar atividades florestais.

3. Auxiliar a elaboração de laudos e documentos técnicos

4. Manter unidades de conservação e de produção, atuar na preservação e conservação ambientais.

5. Fiscalizar e monitorar fauna e flora.

6. Auxiliar profissionais de nível superior na implementação de projetos, gestão ambiental e coordenação de equipes de trabalho

7. Operar máquinas, equipamentos e instrumentos meteorológicos.

8. Participar da coordenação de processos de controle ambiental, utilidades, tratamento de efluentes e levantamentos meteorológicos.

9. Acompanhar e encaminhar os dados recebidos das estações meteorológicas ao setor competente.

10. Orientar e acompanhar os trabalhos de preenchimento dos relatórios, garantindo a exatidão e qualidade das observações meteorológicas.

11. Manter contatos com outras estações ou postos meteorológicos, servindo-se de comunicação formal ou codificados para receber e transmitir informações meteorológicas.

12. Dar suporte à instalação de novas estações agro-meteorológicas ou postos termos pluviométricos determinando local de instalação.

13. Realizar análises físico-químicas e microbiológicas dos efluentes.

14. Organizar a reprodução de animais aquáticos, como peixes, camarões, mexilhões, ostras e rãs, dentre outros.

15. Coletar material de reprodução de animais aquáticos.

16. Controlar sanidade e predação dos animais aquáticos

17. Monitorar qualidade da água, alimentar, capturar e beneficiar animais aquáticos de viveiros, tanques e fazendas marinhas.
18. Prestar assistência técnica e auxiliar a elaboração de projetos, orientando a construção de instalações em fazendas aquícolas e sistema de criação de animais aquáticos.

19. Ministrar treinamentos, participar de projetos e auxiliar em aulas práticas.

20. Zelar pela manutenção, limpeza, conservação, guarda e controle de todo o material, aparelhos, equipamentos e de seu local de trabalho.

21. Participar de programa de treinamento, quando convocado.

22. Executar tarefas pertinentes à área de atuação, utilizando-se de equipamentos de medição e de programas de informática.

23. Executar outras tarefas compatíveis com as exigências para o exercício da função.

(PARANÁ, 2006).

Esses novos profissionais devem controlar as ações de destruição por meio de conscientização, monitoramento, controle, treinando a população para preservar o meio no qual estão inseridos. Pensando em suprir a demanda social é que é ofertado esse curso.

Os alunos que o cursavam eram alunos de classe média, média baixa, a maioria já inseridos no mercado de trabalho, como garçons, caixas de supermercado e/ou farmácia, vendedoras de loja e uma menina (?) que já possuía um filho e que teve que interromper seus estudos para licença maternidade. Concluímos, então, devido ao quadro contextual, que os alunos tinham pressa em terminar seus estudos, nesse caso profissionalizante, para que pudessem atingir um nível mais elevado na sociedade com uma carreira.

Os primeiros meses de sala de aula eram apenas de observação, no qual tínhamos uma carga horária a cumprir, frequentávamos as aulas apenas assistindo sem nenhuma participação, éramos neutros a qualquer ação dentro da sala. Durante esse período de observação ficou evidente que a professora regente da turma em hipótese alguma utilizava textos técnicos em sala, e pudemos ver claramente que isso se dava pelo fato de que a professora tinha uma carga horária semanal de 40 horas com 
turmas variadas entre quinto ao oitavo anos e Ensino médio, técnico e geral, por isso o tempo de preparação de aula era limitado. Além desse fator a falta de preparação linguística, o problema que citamos acima era um fator que prejudicava suas aulas, pois para que pudesse prepará-las com a temática ela precisaria compreender do vocabulário específico. Podemos perceber a questão levantada pelos teóricos acima citados, no caso da profissional responsável por esta classe que possuía o mesmo nível linguístico dos alunos que ensinava e dessa forma, para atender a demanda do curso, era necessário que ela primeiro estudasse o conteúdo para então ensiná-lo. Porém isso era quase que impossível, com a carga de trabalho e a variedade de grupos que a professora possuía. O plano político pedagógico da escola (PPP) visa ao ensino de línguas contextualizado pelo qual os alunos irão aprender a ler textos técnicos objetivando as quatro habilidades: leitura, escuta, fala e escrita, com textos que fossem relevantes aos alunos por meio de textos técnicos da área por eles estudada. Fato é que em 20 horas de observação de aula em nenhuma das vezes a professora trouxe áudio para a sala, bem como nenhum texto no qual a temática tivesse relação com o curso ofertado, havendo assim a escassez de alguns dos objetivos do plano. O conteúdo estruturante do programa era a de prática de leitura com técnicas de skimming, scanning, as quais possibilitam aos alunos o desenvolvimento da compreensão leitora. Em todos os momentos de observação as atividades propostas pela professora eram atividades de tradução nas quais os alunos pegavam o dicionário e traduziam os textos por ela disponibilizados, ou seja, em momento algum foram abordadas técnicas de leitura em sala de aula.

Quando começamos a ministrar as nossas horas em sala de aula, decidimos que iríamos atuar de forma diferente buscando abordar a temática do curso. Portanto, procuramos vídeos que tivessem de alguma forma alguma relação com o ambiental e montamos o nosso material da regência. Escolhemos como gênero a ser trabalhado vídeos institucionais de organizações de preservação ambiental. Sosnowski e Sosnowski (2010) afirmam que as linguagens se manifestam por meio de imagens de modo que podemos fazer a leitura delas para sabermos a sua representação. E por esse motivo optamos pelos vídeos, pois acreditamos que por meio deles os alunos poderão entender o significado do vocabulário abordado por meio da leitura de imagens. Mandarino (2002) comenta que o professor, com a sua perspicácia, pode auxiliar o aluno na leitura de vídeos, mas que para que isso ocorra com sucesso ele precisa estar preparado e ter o conhecimento suficiente das estruturas e da linguagem audiovisual. Segundo a autora "o vídeo pode ser usado como instrumento de leitura crítica do mundo, do conhecimento popular, do conhecimento científico e da própria mídia." (MANDARINO, 2002, p. 4).

No decorrer dessa preparação, entre a procura do vídeo correto a trabalhar em sala de aula, a elaboração da sequência didática que iríamos trabalhar e a aplicação propriamente dita, nos demandou muito tempo, foram tardes sentados na frente do computador para que achássemos o material atrativo e condizente com o tema abordado pelo curso técnico. Além disso, durante o trabalho de estágio tivemos muitas vezes que voltar e adaptar o material para que ficasse de acordo com a proposta que tínhamos em mente. Ficou então claro que, para que possa ensinar em cursos técnicos o professor de LI necessita preparação linguística para abordar os temas de cada curso, o que também não era o nosso caso, pois ambos eu e meu colega possuíamos nível intermediário de inglês, tempo para desenvolver atividades e/ou ao menos material de acordo com as necessidades dos alunos. Os professores deveriam se preparar melhor para abordar os temas técnicos, mas isso é humanamente impossível quando se possui tantas aulas e em diferentes turmas.

Na preparação do material foram escolhidos três vídeos sendo eles Breathe in Breathe out, Global warming (reading INFO) e Money - WWF, os três postados no website Youtube e acessados pelos 
links. O primeiro vídeo apresenta imagens naturais, estas com águas que cobrem a paisagem e com o som da respiração de uma pessoa. Toda vez que há o som de inspiração a água aumenta e com a expiração a água esvazia a cena aparecendo a imagem natural. A primeira imagem é de um rio em meio a pedras e com uma montanha de fundo. A segunda é de um oceano com areia e pedras, quando há a ação da inspiração a água cobre a areia e quando a expiração esvazia. Em seguida um mangue, depois, o oceano novamente, porém dessa vez, com a presença de gelo. A quinta cena do vídeo é mostrado um rio com pedras. Posteriormente uma ilha coberta e descoberta pela água. A sétima um rio no meio das montanhas. E o vídeo acaba com a frase " Half of the oxygen we breathe comes from our oceans. Keep our oceans alive." e o logo da organização responsável pelo vídeo.

O segundo mostra imagens naturais e também informações sobre os problemas naturais que sofremos atualmente. A primeira imagem é a do planeta Terra azul com seus continentes e mares seguido pela terra, mas com resquícios do aquecimento global. A segunda apresenta o índice do uso de energia, seguido pela imagem da Terra em chamas. As imagens seguidas são imagens da natureza sendo elas geleiras, montanhas, a formação de tornados, a comparação entre uma imagem natural em 1941 e 2004, e várias imagens do planeta Terra em condições climáticas variadas. Uma das imagens apresentadas no vídeo mostra explicações sobre o Greenhouse effect, posteriormente uma imagem de um urso polar andando em cápsulas polares derretidas. Outra questão apresentada no vídeo é o aumento de mosquitos e, consequentemente, doenças, devido o aumento da temperatura. A diminuição das geleiras, secas, a ação de indústrias para o aumento dessa destruição entre outras imagens naturais. Como fundo, existe a música do Nickelback - Hero.

O terceiro é uma animação de massinha. Um homem corta uma árvore e a sua ação traz consequências. A árvore derruba outras que bloqueiam a passagem de um rio que se desvia, o que resulta na morte dos peixes e num acidente de máquinas que destroem uma ponte. $\mathrm{Na}$ destruição da ponte um caminhão carregando óleo é derrubado. Todas essas ações são causadas pela atitude do homem. Elas dão a volta ao mundo até voltar ao início o que dá ideia que a conseqüência dos seus atos volta para você. O vídeo é embalado pela música de Liza Minelli e Joel Grey - Money Money. Passamos agora para uma descrição e análise do material elaborado.

\section{O Material e a sua análise}

A sequência didática elaborada inicia com uma apresentação do assunto abordado que é "As consequências das ações humanas". Em seguida, são feitas três perguntas relacionadas ao tema, sendo elas: "O que está acontecendo com a natureza?" e "Você já ouviu sobre algum tipo de destruição? Qual tipo de destruição?" essas duas perguntas foram colocadas para que pudesse ser ativado o conhecimento que os alunos já dispõe sobre o assunto abordado, sendo esta ação relacionada a capacidade de ação.

Então, o vídeo Breathe in Breathe out é exposto aos alunos e seguidamente atividades de informações que devem ser retiradas do vídeo, como: Quem produziu o vídeo?; Onde?; De onde foi retirado?; Qual o propósito do material?; O que acontece no vídeo? E Qual o som? Sendo que essas perguntas fazem parte da mesma capacidade anteriormente citada a capacidade de ação, que visa a buscar o conhecimento prévio do aluno e o contexto no qual o texto apresentado foi produzido.

Posteriormente, é apresentada uma atividade de vocabulário para compreensão das imagens e ainda uma atividade de completar, no qual foram inventadas frases que devem ser preenchidas com a palavra correspondente. Essa atividade faz parte da capacidade linguístico discursiva. 
As atividades a seguir estão ligadas a capacidade de significação. A número 10 da sequência, sendo as perguntas também numeradas, é uma tabela na qual o aluno deve escrever em cada coluna o que acontece nas ações de inspiração e expiração. Na atividade 11 eles irão fazer uma relação entre o ser humano e a respiração. $\mathrm{Na} 12$ os alunos devem analisar a frase do final do vídeo e falar sobre o significado dessa frase.

A de número 13 eles irão fazer frases usando should, must e can. As atividades desenvolvidas já visando à produção do gênero final, por isso, em 14 os alunos devem ir à internet e procurar por imagens relacionadas às frases por eles produzidas na atividade anterior. Essas duas atividades estão relacionadas à capacidade linguística discursiva, pois fazem uso da língua verbal e visual, signos.

As respostas para as perguntas quem produziu o vídeo, onde ele foi produzido, e de onde ele foi retirado, podem ser encontradas no final, no logo do material, este contém o nome da organização que o produziu e o seu site (seria útil reformular o trecho). Podemos perceber que para responder as perguntas os alunos não necessitam de muito conteúdo linguístico, pois as informações e as imagens ajudam na formulação de uma resposta. Ainda por meio das imagens, o aluno poderá deduzir a intenção do gênero ou o propósito do material, descrever o que acontece nele e pelo título do vídeo saber definir o som emitido de fundo. Assim, no próprio vídeo, e fazendo uso da inferência, os alunos podem retirar as informações pedidas pelo professor e ainda algumas atividades apresentam vocabulário novo para que os alunos possam produzir suas próprias frases.

Após uma breve explicação de como construir as frases corretamente (sendo está ainda parte da capacidade linguistic-discursiva), há um texto apresentando o gênero anúncio publicitário institucional e suas características. A atividade 15 diz respeito ao gênero e é abarcada pela capacidade discursiva.

A pergunta 16 faz parte da capacidade de ação, pois questiona o conhecimento dos alunos sobre a organização não governamental que produziu o vídeo, seguida de um pequeno histórico dela. Os alunos irão ler usando as técnicas de leitura para compreensão do texto, que nesse caso poderão ser skimming e scanning, primeiramente uma leitura superficial e então mais detalhada, procurando maiores informações do texto. Então, é apresentado o site Youtube que serviu de suporte para a divulgação do gênero com atividades também relacionadas ao website e sua estrutura, novamente capacidade discursiva.

Com a mesma capacidade, outra etapa se inicia, abordando os elementos contidos no website, para que os aprendizes possam observá-los. Agora éapresentado o segundo vídeo e as atividades seguintes são sobre a estrutura física do site Youtube.

As atividades 20, 21 e 22 são relacionadas à música que compõe o vídeo. O professor irá tocar a música novamente e eles irão dizer o que a música representa de um modo geral. Além disso, é feita uma relação com uma expressão específica, quando o cantor fala de um herói que salvará as pessoas e (a redação é confusa) sobre a frase I'm gonna stand here and wait, com o contexto do aquecimento global. Como se trata da compreensão da letra, a capacidade de significação é abordada.

Após essas atividades, novamente os alunos irão produzir frases acerca do que pode ser feito para melhorar a situação do aquecimento global, esta faz parte da capacidade linguístico discursiva. Segundo as características das atividades e o contexto escolar, podemos observar que os alunos não têm muitas dificuldades em resolver as atividades apenas observando as imagens.

A atividade 25 está relacionada à capacidade de significação, pois o aluno deve responder a pergunta "Você acha que o aquecimento global está afetando as condições da água no mundo?”.

Posteriormente, é feito uma pergunta resgatando o conhecimento prévio do aluno. Esta questão está novamente capacidade de ação e ao tema discutido. 
Em seguida, voltamos à leitura de imagens, na qual ele irá dissertar o que uma determina imagem significa para ele, voltando (evite a repetição de termos) então para a capacidade de significação.

Uma das imagens possui um texto que também foi trabalhado em forma de atividades de compreensão. Para finalizar essa etapa da sequência, são apresentadas mais algumas características relacionadas ao conteúdo gramatical, as quais fazem parte da capacidade linguístico-discursiva. Uma atividade está pedindo que os alunos reescrevam as frases dos anteriores, visando a elaboração dos próprios vídeos. Passamos então para o terceiro vídeo.

Como se trata de um vídeo de outra organização a sequência de atividades se inicia com uma apresentação dela. A primeira atividade de compreensão do funcionamento dessa organização não-governamental. Esta atividade visa à busca do conhecimento do aluno relacionada a esta organização, sendo assim, capacidade de ação.

A atividade 37 está relacionada com a capacidade de significação, pois pede aos alunos a opinião sobre este trabalho. Posteriormente é apresentado o vídeo.

Foi escolhido o vídeo em português para que os alunos pudessem compreender melhor a estrutura do vídeo, fazendo uso da capacidade discursiva e da proposta de Cristovão (2009) em comparar dois textos, um em LE e outro em LM.

As atividades seguintes seguem (evite repetições) a mesma ordem dos anteriores com perguntas sobre o vídeo, apresentação de vocabulário extra e complete, sendo classificadas, respectivamente, capacidade discursiva e linguístico discursiva. Por fim, apresentamos uma revisão de todos os vídeos apresentados, em forma de tabela, na qual há uma mistura das capacidades de ação e significação.

Com todas essas atividades, os aprendizes podem fazer uma leitura do conteúdo do vídeo e chegar a uma conclusão do que se trata por meio das imagens, sendo essa uma leitura estratégica como citado anteriormente. Apesar da possibilidade de resposta apenas por meio das imagens e das informações retiradas dos vídeos, observamos que há a necessidade de complemento para que as atividades possam ser elaboradas com sucesso.

\section{Conclusão}

Nesse quadro político e socioeconômico, compartilhamos da mesma conclusão que Fernández (2008) com relação aos cursos de licenciatura, que as disciplinas devem dialogar de forma que o aluno tenha um conceito tanto do ensino quanto da língua em si. Os professores de LI em cursos técnicos reconsiderariam a temática a ser trabalhada em sala de aula analisando as necessidades dos alunos na aprendizagem da língua inglesa.

Outro fator importante é a ação de linguagem a ser abordada. Sabemos que no contexto de escolas públicas, Ensino Médio técnico, em uma sala de 30 alunos ou, ás vezes, ainda mais, não é possível trabalhar as quatro capacidades. Nesse caso, devendo focar a uma apenas, consideramos nesse contexto mais relevante focar na ação de linguagem leitora com exercícios de compreensão textual. Pensamos também que, ensinando as capacidades de linguagem juntamente com técnicas de leitura, é possível ainda trabalhar vocabulário específico dos temas trabalhados, tornando o conhecimento do aluno mais rico. E quando pensamos em leitura de textos, incluímos aqui os textos orais e a sua compreensão com a leitura de imagens. Acreditamos que com a aquisição de vocabulário específico nas atividades de leitura, seja ela imagética ou não, os futuros técnicos desenvolverão a ação da linguagem oral e/ou textual. Pensamos que as mesmas técnicas de leitura de textos podem ser utilizadas no ensino de orais, nos quais os alunos irão procurar informações gerais e por meio das imagens fazer uma leitura dele e, posteriormente, com o conhecimento linguístico que já possuem, poderão compreender melhor a 
mensagem. Isso não impede que o professor possa adicionar vocabulário extra às atividades, para aumentar o conhecimento do aluno.

Não pensamos que o quadro político e econômico do país exime alunos da possibilidade da efetivação da graduação, os cursos são disponibilizados a população em geral, o aluno apenas precisa estar preparado para os vestibulares ou ter condições financeiras de pagar uma universidade particular. No entanto, se isso não for possível, ele pode optar pelos cursos técnicos para obtenção de uma carreira e partir para o mercado de trabalho, e até que ponto isso prepara bons profissionais para a exigência do mercado? Será que isso não é mais uma tapa buraco? Podemos compreender essa "oportunidade" como apenas, mais uma forma de iludir os cidadãos, os fazendo achar que as condições estão the sendo dadas. Cabe a nós julgarmos se elas realmente estão sendo viáveis.

\section{Referências}

BIANCHETTI, R. G. Modelo neoliberal e politicas educacionais. São Paulo: Cortez, 2001.

BRASIL. Ministério da Educação. Lei $n^{\circ}$ 9.394, de 20 de dezembro de 1996. Estabelece as diretrizes e bases da educação nacional. Brasília, 1996.

BRYDON, D. Local needs, global contexts: learning new literacies. In: MACIEL, R. F.; ARAUJO, V. A. Formação de professores de línguas: ampliando perspectivas. Jundiaí: Paco, 2011. p. 93-109.

CELANI, M. A. A. Perguntas ainda sem resposta na formação de professores de línguas. In: GIMENEZ, T.; MONTEIRO, M. C. G. Formação de professores de línguas na América Latina e transformação social. Campinas: Pontes, 2010. p. 57-67. (Coleção Novas Perspectivas em Linguística aplicada, v. 4.)

CRISTOVÃO, V. L. L. Sequências didáticas para o ensino de línguas. In: DIAS, R.; CRISTOVÃO, V. L. L. (Org.). O livro didático de língua estrangeira. Campinas: Mercado de Letras, 2009. p. 305-344.

CRISTOVÃO, V. L. L.; STUTZ, L. Sequências didáticas: semelhanças e especificidades no contexto francófono como L1 e no contexto brasileiro como LE. In: SZUNDY, P. T. C. et.al. (Org.) Linguística aplicada e sociedade: ensino e aprendizagem de línguas no contexto brasileiro. Campinas, SP: Pontes Editores, 2011. p. 17-40.

CRISTOVAO, V. L. L.; BEATO-CANATO, A. P. M.; PETRECHE, C. R. C.; FERRARINI, M.; ANJOS-SANTOS, L. M. Uma proposta de planejamento de ensino de língua inglesa em torno de gêneros textuais. Letras, Santa Maria, v. 20, p. 191-215, 2010.

FERNANDÉZ, G. M. E. As transformações no mundo de trabalho e as implicações para a formação de professores de línguas. In: GIL, G.; VIEIRA ABRAHÃO, M. H. Educação de professores de linguas: os desafios do formador. Campinas: Pontes, 2008. p. 275-281.

KALVA, J. M.; PENTEADO, A. L. O ensino de inglês instrumental no curso de PROEJA da UTFPR - campus ponta grossa: um estudo de caso. Rehutec: Revista de Humanidades Tecnologia e Cultura, Bauru, v. 1, n. 1, p. 129-146, dez. 2011.

MANDARINO, M. C. F. Organizando o trabalho com vídeo em sala de aula. Morpheus, Rio de Janeiro, ano 1, n. 1, 2002. Disponível em: <http:// www.unirio.br/morpheusonline/Numero01-2000/ monicamandarino.htm>. Acesso em: 9 maio 2012.

PARANÁ. Anexo 2: Res. Conj. N. ${ }^{\circ}$ 002/2006 SETI/SEAP. Disponivel em: <http://www.uel.br/ prorh/carreira/classe_2/tecnico_em_manejo_e_ meio_ambiente.pdf.> Acesso em: 24 jun. 2012.

SABBI, V. A materialização do ideário neoliberal nas políticas educacionais e de extensão do CEFET - PR. In: TEIXEIRA, E. S. (Org.). Educação: algumas reflexões sobre política, teoria e prática. Pato Branco: Liceu Teixeira, 2005. p. 141-154.

SAVIANI, D. Escola e democracia: teorias da educação, curvatura da vara, onze teses sobre a educação política. Campinas: Autores Associados, 2008.

SHIROMA, E. O.; MORAES, M. C. M.; EVANGELISTA, O. Política educacional. Rio de Janeiro: DP\&A, 2002. 
SMITH, A. A riqueza das nações: a investigação sobre sua natureza e suas causas. São Paulo: Nova Cultural, 1996. Disponível em: <http://www. projetos.unijui.edu.br/peteconomia/Adam $\% 20$ Smith\%201.pdf>. Acesso em: 9 maio 2012.

SOSNOWSKI, K.; SOSNOWSKI, M. Professores lendo imagens mediados por tecnologias contemporâneas. In: SEMINÁRIO DE LEITURA DE IMAGENS PARA EDUCAÇÃO: MÚLTIPLAS MÍDIAS, 3., 2010, Florianópolis. Anais... Florianópolis, 2010.

TOZONI-REIS, M. F. C. Educação ambiental: natureza, razão e história. Campinas: Autores associados, 2008. 
